ACCORDING to the foreword, the course on which this book is based aimed at providing both a comprehensive survey of basic topics and a review of some more specialised topics of great current interest and intrinsic importance. On that criterion it fails. For example, I find it hard to find the great current interest or intrinsic importance in a three page contribution on rocket soundings in Poland. But then, I'm not Polish.

Had this book been the proceedings of a conference of atmospheric specialists then its contents could not have been faulted, but on the basis of the stated aim I have a vision of eager young workers, new to aeronomy, lusting for understandable and interesting surveys. What they will receive is a set of 16 uncoordinated and rather specialised lectures that present an unbalanced view of the upper atmosphere.

I graded the articles for interest and clarity by pretending that I was a first year graduate student. The results:

$\alpha$ : Tides (Lindzen), Electrical Structure (Webb), Rockets and $\mathrm{Re}$ mote Sensing (Heath et al.), Lower Ionosphere Morphology (Harnismacher), Winds and Turbulence (Muller), The F Region (Rishbeth).

B: Photochemical Models (Hesstvedt), D Region Measuring Techniques (Rumi), Composition Studies (Van Zahn), Corpuscular Effects (Mariani).

$\gamma$ : The other six articles.

The $\gamma_{\mathrm{S}}$ account for only 50 pages, but their omission would have im-

\section{Air text}

\section{Tom Beer}

Structure and Dynamics of the Upper Atmosphere. (Proceedings of the Second Course of the International School of Atmospheric Physics.) (Developments in Atmospheric Science, 1.) Edited by Franco Verniani. Pp. xiii+ 535. (Elsevier Scientific: Amsterdam, Oxford and New York, 1974.) Dfl. 160; $\$ 61.50$.

proved the book. They are low quality research contributions that should have been sent to the appropriate research journals. It is a mockery to have a four page article grandiosely entitled "MidLatitude Sporadic E" (Bossolasco and Elena); it fails to do credit to an exceedingly important subject.

Had I graded the contributions in terms of their completeness then almost all of them would have been relegated to the $\beta$ s and $\gamma \mathrm{s}$. We are presented with 40 pages on winds and turbulence in the meteor zone without the merest whisper of sporadic $\mathrm{E}\left(\mathrm{E}_{\mathrm{s}}\right)$. Harnismacher, to his credit, includes $\mathbf{E}_{\mathrm{s}}$ morphology in his excellent contribution but it would come as a surprise to Verniani's scholars at Erice that theories actually exist to account for


after 535 pages of heavy monologue, unaware of spread $F$, polar cap absorption, the plasmapause, the polar wind, incoherent scatter radars, the acoustic cutoff frequency, aurorae and the details of the dynamo current.

Overall, I think the editing was lamentable. The greatest omission was of an introductory chapter that defined a few things. Like: upper atmosphere, ionosphere, stratosphere, D region, and so on. Also, the book is a very uneven mix between theory and experiment. Some topics (such as tides) are only dealt with theoretically, and only the experimental details of others (for example, lower ionosphere) are presented. To complete the confusion, half of the articles use c.g.s. units whereas the other half use m.k.s.

On the credit side, the editor has carefully systematised everybody's bibliographies; the author index and subject index are well prepared; there are surprisingly few typographical errors, and Elsevier have done a fine job on the printing and binding. I unintentionally dropped the book from the back of my speeding motor scooter, an event which the binding has uncomplainingly accepted.

I would only recommend this book to those already actively engaged in work on the upper atmosphere. A few of the articles are excellent, though the active worker will have seen much of the material before in one form or another. Aeronomy desperately needs a lot less edited collections of unrelated papers and a few more single or co-authored works of simple exposition and of authority. I hope that Developments in Atmospheric Science, 2 provides the latter.
THIs book would make a good present for the serious aquarist and would be a useful addition to any departmental library which gives a thought to fostering an interest in freshwater fish and their care. It is not a new book, but a new edition of an old one. An earlier issue was reviewed by Phillip Greenwood in these pages (Nature, 198, 516; 1962) and he found much good in it. I concur with his view.

The new edition is compact, strongly bound, and presented as two volumes. The bulk of the text comprises descriptions of the species grouped by families. Each description contains general information at the family level, with distribution charts; and the accounts of the species include more detailed material, biometric data, and illustra- has been somewhat reduced and tions. For the aquarist's special needs although this makes the book more information as to behaviour, food compact, there is the disadvantage that

ing, are also given.

Some changes have been made in the

\section{Fish out of date}

\section{F. R. Harden Jones}

Freshwater Fishes of the World. By Gunther Sterba. Vol 1: pp. 1-456; vol 2: pp. 457-877; 191 plates. (Studio Vista: London, 1974.) $£ 12.50$. preferences, and environmental require- drawings originally scaled to natural ments with special reference to breed- size are now $10 \%$ too small.

new edition. Illustrations that were - what book is free from these?-and coloured in previous editions are here I would be disappointed to learn that in black and white, and a whole sét of they had been carried through from new colour photographs have been in- earlier editions. And no changes have been made to the select bibliography, in which the most recent publication is dated 1962; for $£ 12.50$ a purchaser could expect to be taken into the 1970 s. 